the patient sank gradually. Sydenham has said, and after him Van Swieten and Stoll have repeated, that when there is no tumefaction of the face and eyelids in variola, death takes place on the ninth or tenth day, if the disease is discreet, and on the thirteenth or fourteenth if it is confluent. The exactness of this rule was exemplified in the instance $I$ have mentioned. At the autopsy no lesion was found, except pulmonary congestion.

\section{REPORT OF A CASE OF ANEURISM OF THE CAROTID ARTERY.}

By G. Whime, Esq., F.R.C.S., Surgeon to the General Hospital, Nottingliam.

Mr. $\mathrm{H}-$, aged thirty-four, printer, of middle stature, rather spare habit, health generally rather delicate, habits not very temperate. Between three and four months ago obserred a small lump on the right side of the neck ; it gradually increased till about a month back, when, having some cough, and his roice becoming hoarse, he called on his usual medical attendant, who directed him to paint the tumour with tincture of iodine, and to go to the sea-side. He returned a few days ago, in consequence of the lump having grown very rapidly, and become tight and uneasy, and having a throbbing sound and feel, which prevents him sleeping. He thinks the lump is double the size it was a fortnight ago ; his medical attendant says it has visibly increased the last two days. The tumour, at the present moment, is of considerable size, occupying the right side of the neck, from just below the ear, to within two fingers' breadth of the sternum; the larynx is pushed considerably to the opposite side, and the sterno-cleido-mastoid muscle is forced outwards and backwards. The integument is, in places, of a dark colow, and there are two small superficial ulcers, produced, probably, by the iodine. There is no heat, and but slight tenderness of the tumour, which is firm, elastic, and pulsates perceptibly, both to the eye and touch, in every part; by the aid of the stethoscope, a loud biowing sound is heard at each pulsation. The right temporal artery beats more feebly than the left, the pulsation of the right carotid, below the tumour, cannot be felt; but very firm pressure over the situation of that vessel arrests the pulsation of the tumour. The patient says the tumour commenced at the upper part of the neck, and gradually extended downwards as it grew larger. In consultation, (present, Drs Williams, sen. and jun., Mr. Davison, Mr. T. N. Thompson, Mr. White, Mr. Sibson, Mr. Stanger, it was agreed that the tumour was an aneurism of the carotid, and that it was possible and expedient to place a ligature upon that artery below the tumour. The patient's bowels having been freely opened the day before by a blue pill and compound rhubarb powder, the operation was immediately performed, (10 A.M., August 28th, 1845.) The patient being laid on a table, in such a position that the light fell directly on his neck, an incision, about two inches long, was made through the integuments in nearly a perpendicular direction, and terminating at the inner margin of the attachment of the sterno-mastoid muscle to the sternum, the upper part of the incision being between the tumour and the trachea. This exposed a large vein, round which two ligatures were placed, and the vein divided between them. The fascia and some loose cellular tissue were next divided, and the edge of the sterno-hyoidens brought into view. Crossing the upper angle of the wound was just seen the omo-hyoideus. At this stage of the operation, very moderate pressure with the point of the finger at the bottom of the wound arrested the pulsation of the trimour; but the beating of the carotid could not be felt. The sides of the wound were held asunder by blunt hooks, and the wound kept clean by small bits of sponge, put to the bottom of it by means of forceps. With the forceps and scalpel the sheath of the artery was now scratched throngh, a nerve (descendens noni) was seen, and pulled aside by the blunt hook, and the artery was fully exposed. An armed aneurism-needle was, with some difficulty, passed behind it from the outer side; but from the great depth and narrowness of the wound, the needle's point could not be brought forward on the inner side of the vessel. The needle was therefore withdrawn, and another, the curre of which formed a segment of a much smaller circle, was introduced with facility. The artery, as it now lay on the aneurism-needle, was compressed with the tip of the finger, and the tumour's pulsation was found to be commanded; the pulsation in the vessel itself was very feeble. The needle being withdrawn, and the ligature firmly tied, the edges of the wound were brought together by two points of suture, and some strips of Macord's plaster.
The patient was then put to bed, and the wound and tumour kept covered by pieces of linen wrung out of cold water. Scarcely an ounce of blood was lost during the operation. The ligature employed was a firm round hemp, one of mode. rate thickness. Before commencing the operation, the patient was desired to exhale completely, and to keep his chest as empty as possible. While in this state, the upper part of the chest was closely surrounded with a very long firm bandage, and he was instructed to respire, as much as practicable, by the diaphragm and abdominal muscles. By this means the length of the neck was materially increased, and the cervical veins were prevented from being alternately disteinded and emptied. This ingenious method was suggested by Mr. Sibson, our resident hospital surgeon, and I feel sure very much facilitated the operation. It is remarkable that the internal jugular was not seen, and the descendens noni the only nerve exposed. To have gruel, tea, dry toast, and toast-water.

Aug. 29th.-Makes no complaint; no pain in the head, or any uneasy sensation. Has not slept much; but has had a more comfortable night than for some time past, owing to the absence of the beating in the neck and ear. Pulse 90, and soft; no pulsation in the tumour or right temporal artery; slight oozing from the wound, just sufficient to stain the wetcloths.

30 th.-Makes no complaint; not much sleep; pulse 86 , and soft; bloody oozing continues.

31st.-Rather more sleep; no pain; pulse 86; complains of hunger; bloody oozing contimues, though very slight. To have some broth. To talse a simple aperient mixture.

Sept. Ist.-Broth made him sick; says it generally has that effect. Bowels opened twice; pulse 90 ; skin cool; still some bloody oozing; have removed the two sutures; no adhesion; no inflammation: some black coagulum occupies the bottom of the wound. Lint dipped in cold water to be applied. 'To have a mutton chop.

2nd.-Sixth day. Slept rather better the beginning of the night. About two o'clock in the morning was rather sick; retched a little, and brought up some dark-coloured mucus; shortly afterwards felt something trickling down the neck; found it was florid blood. The bleeding was quickly arrested by making pressure on the wound, with a sponge wrung out of cold water; about two or three ounces were lost; no pulsation in tumour or temporal artery. Repeat the cathartic draught in the morning. 'Pulse 90, and soft.

3rd.-Bowels have acted twice; pulse 90; some good sleep; slight bloody discharge from the wound. To have milk and bread; no meat. The two ligatures which tied the vein have come away.

4th.-Discharge still slightiy bloody; the tumour seems less tense, and somewhat smaller.

5th.-Makes no complaint; pulse 86.

6th.-Tenth day. The ligature that surrounds the artery was found loose in the wound; discharge still bloody, but lithle in quantity; wound grannlating, and nearly free from coagula. Continue mills diet.--Fight x.x.: Ilæmorrhage to the amount of at least a pint, within the last twenty minutes; somewhat restrained by pressure with the cold sponge; blood still wells out from under a small dark coacnimm at the very bottom of the wound. The wound filled with lint, and a large graduated compress placed over it, and some pressure kept up by means of strips of adhesive plaster, and a bandage passed in the figure of 8 under the arms. Felt faint a few minutes ago, bat that has gone off. Pulse 120, and very weak; great restlessness. To take half a grain of acetate of morphia.

7th.-Passed a tranquil nicht. Early this morning the hremorrhage recurred, to the amount of three or four ounces, but ceased spontaneously; makes no complaint, but of weakness. To have tea, gruel, tcast-water, and bread soaked in milk and water. Pulse 100. Repeat the half grain of morphia at bed-time.

8th.-Passed a good night; pulse 100, and soft; the wound is filling up with granulations; a small black spot of coagulum still remains at the bottom of the wound; discharge slightly bloody. Repeat the half grain of morphia at bed-time; tincture of digitalis, twenty minims, to be taken twice a day. Has been removed to another bed, and his clothes changed. A board was placed under the mattress so as to maintain him in a slightly oblique posture.

9th.-A good night; bowels opened twice; pulse 90 ; discharge less coloured.

12th.-Wound filled up with large granulations; discharge small in quantity, and free from bloody stain; no appearance of dark spot in the wound. Continue tincture of digitalis.

16 th. - Feels well but rather weak; wound cicatrizing; is tonched daily with nitrate of silver, and covered with dry lint; pulse 76 ; tumour is smaller, evidently contains fiuid; 
the integuments have regained their natural colour; one superficial ulceration still remains; no pulsation in tumour or temporal artery.

20th. Continues to improve; wound healing; complains of nothing but want of solid food; has good nights; sits up during the greater part of the day in the sitting-room; has mutton or partridge daily. Omit the tincture of digitalis.

25th.-Continues to improve ; is allowed to walk about quietly, and to have a short drive out daily; sleeps well; appetite good, but is restricted to one small meat-meal daily; pulse 80 ; wound cicatrizing; no pulsation in tumour or temporal artery.

Oct. 20th.-Feels well; goes to his employment in the printing-office; is desired to use great cantion in the use of stimulants, and to avoid violent exertion of any kind; the wound is as nearly closed as possible.

Nov. 16th.-Continues well ; the tumour has diminished much in size during the last fortnight, it is soft and evidently contains fluid; the integument is loose and of a natural colour no pulsation can be detected in the tumour or temporal artery; a little pus still oozes from a minute opening near the upper extremity of the wound.

Dec. 15th.-Wounds have been quite healed for some time past; the tumour has diminished to about one-sixth of its original size, and has become much more solid; the voice is still rather hoarse; general health quite good.

The forefoing case proves the practicability of successfully placing a ligature on a large arterial trunk, very near to its origin. The facility with which a formidable hæmorrhage was arrested, occurring immediately after the separation of the ligature, is deserving of notice. Was it not from the portion of the artery connected with the tumour that the bleeding took place?

Nottingham, January, 1846.

\section{ON ANTEVERSION OF THE UTERUS.}

By Conway Thomas Edwards, Esq., M.D., Walcot Parade, Bath. THE recital of numerous cases of anteversion of the uterus has at length, I believe, settled the question as to its existence at all, in the minds of almost all medical practitioners; and although it must be allowed that it is an affection, in its full extent, rarely met with, and requiring most careful examination (especially in its earlier stages, when it may, indeed, be passed over by the physician, and be by the patient unlieeded) for its correct diagnosis, yet, from frequent opportunities of investigation, I am convinced the displacement, in a slight degree, is of more frequent occur rence than it is usually considered, although $I$ cannot by any means go the length of affirming, with M. Listianc, that anteversion is far more frequent than retroversion.

Within the last four years I have been applied to by several persons complaining of symptoms similar to those of this displacement, and upon examination per vaginam, their true character has been unequivocally discovered. In one of these the patient was unmarried, but, as it afterwards turned out, was six weeks gone in pregnancy: she attributed the mischief to having been knocked down by a horse whilst crossing a road. There was here great pain and difficulty in passing the urine, but none in defecating. The other symptoms were not well marked; she only complained of a heavy sensation in the pelvis on standing erect; vaginal examination, however, was quite confirmative. The recumbent posture was ordered to be maintained, the rectum kept well emptied, and, in the course of ten days, the uterus had righted itself.

Two of the other cases mentioned above were young females, the one seventeen, and the other nineteen, years of age. No cause could be attributed, but from the condition of the uterus, as well as from the success of the treatment adopted, I believe congestion was the chief. In the former, menstruation had been regular; in the latter, irregular.

The following case I have drawn out in full, as being that most strongly marked, and detailing well the symptoms of that peculiar displacement.

MIS. M. A- , a thin and 1ymphatic person, aged fortytwo, applied to me, August 10th, 1845; she was married at the age of thirty-four; has had two children, the one being six, the other two and a half years of age. The catamenia appeared unusually late in life, not until the nineteenth year, previous to which time her health was always uncertain; subsequently, however, it has improved, and until about two months since has been good, with perfect regularity in her monthly periods. At that time (June) she commenced to experience slight bearing-down pains, with a sense of heat behind the pubis, and a dull aching in the back. This was attended with a leucorrhœal discharge, very small in quantity, and once or twice, as she affirms, being streaked with blood. She was not "unwell" on last expecting to be so. These symptoms continued much about the same until ten days since, when, visiting a friend by the sea-side, she went out for a sail, which produced a considerable degree of sea-sickness; shortly after this, the pains before experienced increased, and were attended with new features, such as repeated attempts and difficulty in passing the urine. This led her to apply for advice.

Present condition.-Complains of a weight low down in the pelvis, especially behind the pubis, with a disagreeable sensation of irritation about the rectum, rendering her frequently inclined to try and evacuate its contents; the bowels are usually constipated, but after aperient medicine has been taken defecation is but very slightly painful or difficult; her bladder is extremely irritable, can retain the urine but a short time, and passes it with acute pain and difficulty; she has "a teasing pain" in the lower part of the back, occasionally passing down the thigh; exertion aggravates all the symptoms; standing erect likewise; her easiest posture is on the back, with the lower extremities flexed; complains now and then of sickness after taking food; the tongue is coated with a thin white fur; pulse 82 , rather hard; vaginal discharge but trifling, inodorous, yellowish, and somewhat tenacious; there appears to have been symptoms of spinal irritation for some time, which, from reflection, might occasion the uterine excitement; the os uteri conld not be brought into view with the speculum: the finger discovered the vagina of higher temperature than usual; anteriorly, a large hard tumour is felt towards the pubis, which is tender on pressure the neck of the uterus is also large, and directed backwards; the "mouth" cannot be reached except when the tumour in front, formed by the body of the organ, is pushed upwards, when the neck becomes a little depressed; the bowels have not been open for two days. Fifteen leeches to the hypogastrium; the bleeding to be encouraged by warm poultices; extract of colocynth and liyoscyamus pills to be taken directly, and to be followed by an enema. The recumbent posture to be rigorously observed.

11th. - The bowels have been freely opened; the tenderness less over the hypogastric region; micturition most painfu and frequent, so much so as to make the patient eagerly call out for relief by mannally rectifying the position. This was acceded to. The patient was placed upon lier back, with the pelvis elevated and the thighs flexed. The rectum having been thoroughly cleansed by an enema, the fore and middle fingers of the right hand were passed up to the cervix, whilst the forefinger of the left hand elevated the fundus of the organ, which, by depressing the cervix, enabled the finger to be passed round it, when, by gentle traction, assisted by the elevation of the "fundus," in the course of a short time the uterus regained its normal position. The recumbent posture was ordered particularly. The leeches to be repeated. A draught of hyoscyamus to be given at once, and to-morrow morning a gentle aperient prescribed.

12th.- Has passed a comparatively comfortalule night; all the symptoms have considerably abated; there is still a little pain in micturition; bowels relieved. An injection of the compound solution of alum to be employed.

14th.-Going on well; the uterus maintains its healthy position; still a little "bearing-down" sensation felt at times; the cervix uteri still harder and larger than usual; examination by the aid of the speculum discovers a small superficial ulceration existing on the back part of the neck, extending almost to the "os." This was touched with the nitrate of silver, as recommended by Dr. Bennet, and the injection ordered to be continued. A pill of disulphate of quinine and sulphate of iron was directed to be taken twice or thrice a day.

From this period but little of interest occurred; suffice it to say, that in a month from this date (the 20th) she had all but regained her wonted strength; had meustruated, although in quantity not so great as usual, and had lost all pain and irritation about the bladder; the ulceration completely healed about ten days after, under the re-application of the caustic; the discharge has completely ceased.

Remarks.-The causes, generally, of anteversion of the uterus are obscure. It has been seen from infancy to old age, nor is pregnancy a very active cause, although of the cases recorded a great number have been connected with it. A relaxed condition of the vagina, as well as a great breadth of it, have 